\title{
VALORAÇÃO DO CONHECIMENTO: SIGNIFICAÇÃO E IDENTIDADE NA AÇÃO ORGANIZACIONAL
}

VALUING KNOWLEDGE: MEANING AND IDENTITY IN ORGANIZATIONAL ACTIVITIES

VALORACIÓN DEL CONOCIMIENTO: SIGNIFICACIÓN E IDENTIDAD EN LA ACCIÓN ORGANIZACIONAL

\section{RESUMO}

A valoração do conhecimento representa uma lacuna na área do conhecimento organizacional. Esse artigo visa responder quais processos são adotados pelos indivíduos para a valoração dos conhecimentos nas organizações. A pesquisa, realizada com profissionais de $\mathrm{RH}$, utilizou grounded theory method. Os resultados sugerem que o processo de identificação dos indivíduos com a identidade organizacional ocupa um lugar central na valoração do conhecimento. A organização, por intermédio da alta gestão ou das rotinas organizacionais, surgiu como "O

outro" que parece conduzir as diretrizes a serem seguidas, assim como quais conhecimentos avaliar e valorar; aquela com quem os membros organizacionais buscam identificar-se. Os indivíduos expressaram mecanismos de afirmação, adequação ou reconstrução de suas identidades a fim de gerar, justificar ou negar identificação com a organização. É sugerido que o modelo de comando vertical ainda prevalece sobre a interação horizontal, tornando difícil o estabelecimento de conhecimento emergente entre os membros organizacionais.

PALAVRAS-CHAVE Conhecimento organizacional, valoração do conhecimento, identidade organizacional, identificação, grounded theory method.

Andrea Cherman acherman@iag.puc-rio.br

Professora do Instituto de Administração e Gerência IAG, Pontifícia Universidade Católica do Rio de Janeiro - Rio de Janeiro RJ, Brasil

Sandra Regina da Rocha-Pinto sanpin@iag.puc-rio.br

Professora do Instituto de Administração e Gerência IAG, Pontifícia Universidade Católica do Rio de Janeiro - Rio de Janeiro RJ, Brasil

Abstract Knowledge assessment represents a gap in the area of organizational knowledge. This article seeks to determine what means are adopted by individuals in evaluating the knowledge of organizations. The research employed the grounded theory method and was carried out by human resources (HR) professionals. The results suggest that the process of providing individuals with an organizational identity occupies a central place in knowledge valuation. The organization has emerged as "the other" by means of senior management or organizational routines and this appears to have led to the guidelines that must be followed as well as the type of knowledge to be appraised and evaluated - a kind of knowledge with which the members of the organization can seek to be identified. Individuals devise mechanisms of self-affirmation, cultural adaptation or reconstruction with regard to their identities, with the aim of bringing about, explaining or denying their identification with a company. It is suggested that the vertical control model still prevails over horizontal integration and this makes it difficult to ensure that the emerging knowledge is established among the members of the organization.

keywords Organizational knowledge, knowledge valuation, organizational identity, identification, grounded theory.

Resumen La valoración del conocimiento representa una laguna en el área del conocimiento organizacional. Este artículo se propone responder cuáles procesos son adoptados por los individuos para la valoración de los conocimientos en las organizaciones. La investigación, realizada con profesionales de RH, utilizó el método grounded theory. Los resultados sugieren que el proceso de identificación de los individuos con la identidad organizacional ocupa un lugar central en la valoración del conocimiento. La organización, por intermedio de la alta gestión o de las rutinas organizacionales, surgió como "el otro" que parece determinar las directrices que deben ser seguidas, así como cuáles conocimientos evaluar y valorar; aquella con quien los miembros organizacionales buscan identificarse. Los individuos expresaron mecanismos de afirmación, adecuación o reconstrucción de sus identidades a fin de generar, justificar o negar identificación con la organización. Se sugiere que el modelo de comando vertical todavía prevalece sobre la interacción horizontal, haciendo difícil el establecimiento de conocimiento emergente entre los miembros organizacionales.

Palabras clave Conocimiento organizacional, valoración del conocimiento, identidad organizacional, identificación, método grounded theory. 


\section{INTRODUÇÃO}

É reconhecida a relevância da questão do conhecimento para o contexto organizacional, especialmente quando ligada às correntes estratégicas baseadas em recursos (BARNEY, 1991; PENROSE, 1956; WERNERFELT, 1984) e em conhecimento (GRANT, 1996; PRAHALAD e HAMEL, 1990; SPENDER e GRANT, 1996). Em tais abordagens, recursos, capacidades e competências, na forma de ativos de conhecimento, tornam-se peças-chave para a empresa obter vantagem competitiva sustentável e melhorar o desempenho organizacional. Nonaka, Toyama e Byosière (2001) apontam que a captura do valor do conhecimento ainda é um tema a ser explorado. Embora os autores estivessem se referindo a um valor mensurável por algum sistema organizacional contábil, a revisão da literatura nacional e internacional dos últimos 10 anos sobre o tema de valoração do conhecimento revelou que o enfoque com base na percepção dos indivíduos ainda permanece subexplorado.

No presente trabalho, procurou-se abordar o tema do conhecimento nas empresas como ação organizacional, a perspectiva do conhecer organizacional (knowing), construído nas práticas coletivas (COOK e BROWN, 1999; GHERARDI, 2006), na ação em fluxo dinâmico, contínuo e relacional (BROWN e DUGUID, 2001; LAVE e WENGER, 1991; WENGER, 1998, 2000). O conhecimento, enquanto conhecer (knowing), é uma prática na ação, permanente, realizada pelos membros, que constitui a própria organização, suas rotinas e seus significados, (GHERARDI, 2006), e que contribui com a construção de suas identidades (BROWN e DUGUID, 2001; CORLEY e GIOIA, 2003; ELKJAER, 2003; LAVE e WENGER, 1991).

O objetivo deste estudo foi identificar os processos e mecanismos adotados pelos indivíduos para a valoração do conhecimento na organização. Foi utilizado o grounded theory method (GTM) na pesquisa empírica, com profissionais de RH. Como principal contribuição, o estudo sugere que persistem modos de controle organizacional tradicionais sobre os membros organizacionais, em que a identidade organizacional (IO) atua como meio de comando-controle, parecendo orientar o uso da capacidade dos indivíduos na obtenção das diretrizes organizacionais.

O trabalho está organizado em seis seções, incluindo esta introdução. A segunda aborda o marco teórico utilizado; a terceira expõe os procedimentos metodológicos; a quarta apresenta a análise e as ca- tegorias emergentes; a quinta discute os resultados encontrados; a sexta conclui com as limitações, a contribuição do estudo e as sugestões para futuras pesquisas.

\section{FUNDAMENTAÇÃO TEÓRICA}

\section{Conhecer (knowing) organizacional}

No presente estudo, considerou-se a organização como uma coleção de práticas coletivas (BROWN e DUGUID, 2001; LAVE e WENGER, 1991). Nesse sentido, a organização não é uma realidade objetivada, dada, mas uma realidade criada na ação organizacional. No fluxo de atividades, processos, sistemas, rotinas, crenças, cultura e informação, a organização é permanente e continuamente construída e reconstruída pelos indivíduos em sua ação, que interpretam, reinterpretam, configuram e reconfiguram a organização em um movimento de sensemaking (WEICK, 1995).

Cook e Yanow (1993) argumentam que o conhecimento é algo local, situado naquele mundo social chamado organização, onde as pessoas se encontram para produzir e fazer sentido enquanto trabalham. Do modo como as coisas são feitas, o conhecimento é criado (BROWN e DUGUID, 2001; LAVE e WENGER, 1991; WENGER, 1998), ou seja, a criação refere-se diretamente à experiência humana, e a origem do conhecimento é a experiência vivida (ELKJAER, 2003).

Contu e Willmott (2003) contribuem ao enfoque, abordando como as questões de poder, controle e política existentes nos contextos sociais, no âmbito das organizações, influenciam na integração do conhecimento pelos indivíduos e coletivos (ANTONACOPOULOU, 2006; OBORN e DAWSON, 2010), na aquisição de novos conhecimentos para mudança estratégica (NAG e outros, 2007) e na transferência de práticas locais para a matriz (HARMAN, 2012).

Hedberg e Wolff (2001) ressaltam que, no fluxo de atividades e processos, a forma como a organização concebe a si mesma e o seu ambiente poderá impactar nas suas opções estratégicas e também moldar sua capacidade de aprender com sua própria ação organizacional (HEDBERG e WOLFF, 2001; STARBUCK, BARNETT, BAUMARD, 2008; STARBUCK e HEDBERG, 2001). Portanto, se poderia supor que o conhecimento valorado tende a ser incorporado mais facilmente nas práticas, sistemas, cultura e processos 
organizacionais, e ser vivenciado na ação (de trabalhar) pelos indivíduos.

Ressalta-se que ação vivida não diz respeito, apenas, à aquisição de conhecimento; trata-se, também, de aquisição de identidades pelo trabalho de encaixe dos indivíduos no grupo e na organização (CORLEY e GIOIA, 2003; WEICK, 1995). Os indivíduos não aprendem apenas acerca de algo, mas também aprendem a ser naquele contexto (BROWN e DUGUID, 2001; ELKJAER, 2003; HANDLEY e outros, 2007). Esse ponto é aprofundado no tópico Conhecimento, identidade e valoracão.

\section{Identidade e identificação nas organizações}

Identidade define o que a entidade - seja o indivíduo, o grupo ou a organização - é, em uma tentativa de definir a si mesma. No nível organizacional, a identidade diz respeito a capturar o que proporciona significado para os níveis acima e além dos seus membros, isto é, um significado autorreferencial, onde o self é coletivo (CORLEY e outros, 2006).

Há certo consenso, entre os autores, de que a IO envolve um entendimento compartilhado por um coletivo. A partir daí, porém, diferentes visões resultam sobre a interação entre os níveis individual e coletivo. Uma dessas visões aponta que IO é um fenômeno que existe apenas no nível do ator social e rejeita a ideia de uma crença coletiva (WHETTEN e MACKEY, 2002). Outra visão argumenta que a IO é a cognição no nível individual sobre "O que a organização é" (DUTTON, DUKERICH, HARQUAIL, 1994), em que há uma relação dialética entre o coletivo e as cognições individuais construídas, que pode ser chamada de identidade organizacional construída ou percebida (HARQUAIL e KING, 2003). Corley e outros (2006) propõem, então, que IO seja o termo usado para descrever a identidade como um coletivo, enquanto o termo organizationally based identity seja empregado para descrever a parte desse autoconceito que define a conexão do membro individual com a organização: a identificação.

Ainda segundo Corley e outros (2006), a IO é concebida como um fenômeno experimentado pelos membros organizacionais, percebido pelos outsiders e central para os processos sociais, com resultados reais nos contextos organizacionais. Nessa visão, as identidades no nível coletivo podem ser distintas das identidades no nível individual, embora estejam relacionadas, e capazes de ser modeladas nos processos sociais na organização. Essa concepção como fenô- meno é relevante, dado o paradigma interpretativista. Assim, a IO é uma construção social contínua que tem lugar entre os membros organizacionais; pode ser influenciada e acessada pelos indivíduos, grupos, alta gestão ou outros coletivos; e é geralmente entendida como focada na organização. Os membros organizacionais, por sua vez, fazem uso de narrativas e outras abordagens para articular, negociar e substanciar as identidades, operando o sensemaking (WEICK, 1995) para fazer sentido de suas identidades na(s) realidade(s) vivida(s) na organização.

Por sua vez, a identificação tem o papel de incorporar os indivíduos nas identidades relevantes para eles (ASHFORTH e outros, 2008). Significa que o indivíduo se autodefine ao ver a definição coletiva ou os papéis; ou seja, quando o autoconceito do indivíduo contém os mesmos atributos percebidos na IO (DUTTON e outros, 1994). A identificação é uma relação entre os três níveis da identidade: 1) o centro da identidade apresenta os conceitos de autodefinição (eu sou), de atribuição de importância (eu valoro) e de afeto (eu sinto); 2) o conteúdo da identidade - o que significa ser aquele indivíduo - apresenta os valores (eu me importo), metas (eu quero), crenças (eu acredito), traços estereotípicos (eu faço) e conhecimentos, habilidades e capacidades (eu posso); e 3) comportamentos da identidade (eu me comporto) (ASHFORTH e outros, 2008). A identificação é o processo pelo qual o indivíduo se define, comunica tal definição aos outros e se utiliza dessa definição para guiar sua vida e trabalho; contribui para o sentido de pertencimento do indivíduo na organização ou nos grupos, afetando sua autoestima e/ou motivando-o para o autodesenvolvimento (ASHFORTH e outros, 2008).

\section{Conhecimento, identidade e valoração}

A relação entre conhecimento organizacional e identidade foi estabelecida desde os primeiros trabalhos do conhecimento na ação organizacional (BROWN e DUGUID, 2001; LAVE e WENGER, 1991; WENGER, 1998, 2000). A partir de então, foi abordada e desenvolvida por meio de diversas vertentes: pela aprendizagem na ação organizacional (HANDLEY e outros 2007) no setor público (HARMAN, 2012); na reação à mudança organizacional (BROWN e STARKEY, 2000) e tecnológica (SCHWAR e WATSON, 2005); na questão da transferência de conhecimento (KANE, 2010); na adesão aos programas de gestão (RAVISHANKAR e PAN, 2008); no papel das identidades sociais na 
geração de conhecimento (ROBERTSON e outros, 2003), com atenção ao conhecimento especializado (HANDLEY e outros, 2007; WARING e CURRIE, 2009).

Por sua vez, a ligação entre valoração do conhecimento organizacional e identidade foi pouco tratada na literatura do conhecimento organizacional. Menon e Blount (2003) e Gao e Riley (2010) relacionaram a valoração do conhecimento nas organizações pelas percepções dos membros por seus pares e grupos aos quais pertencem, por meio da teoria da identidade social (centrada nos trabalhos de TAJFEL, 1978; TAJFEL e TURNER, 1979; TURNER, 1982, 1985). Os autores identificaram esquemas relacionais e identidade profissional como mediadores nos processos de atribuição de valor ao conhecimento.

Já Corley e Gioia (2003) e Nag e outros (2007) abordaram a discussão do conhecimento organizacional pela esfera da identificação organizacional. Os autores trataram das identidades em momentos de mudança organizacional, quando a aprendizagem, o conhecimento e a construção do significado são processos fundamentais. Para Corley e Gioia (2003), o contínuo processo de aprendizagem nas organizações é essencial para a construção e reconstrução da IO. Segundo Nag e outros (2007), os modos por meio dos quais os membros utilizaram o conhecimento nas suas práticas diárias afetaram e foram afetados recursivamente pela noção coletiva de quem eles eram enquanto organização (IO), e as relações de poder e controle evidenciaram-se quando os gerentes tentaram modificar sua identidade e/ou suas práticas. Estudos apontam que a ameaça à IO está relacionada negativamente à criação de valor (BROWN e STARKEY, 2000; NAG e outros, 2007), pois os indivíduos protegem sua autoestima por meio da continuidade da IO existente, deixando, assim, de contribuir com a organização ou valorando aqueles conhecimentos da organização com que mais se identificam (RAVISHANKAR e PAN, 2008).

\section{METODOLOGIA DO ESTUDO}

Este estudo teórico-empírico adota o paradigma interpretativo. Sob esse enfoque, a realidade ou mundo social é um processo social emergente, criado pelos indivíduos com base em suas experiências subjetivas naquele contexto social, cujos significados são intersubjetivamente compartilhados. Os indivíduos são atores das ações organizacionais, e não meros obser- vadores passivos, ou seja, atuam na construção daquele mundo social, por meio das suas interpretações subjetivas e do compartilhamento de ressignificações coletivas de suas experiências (BURRELL e MORGAN, 2003). Na dimensão do conhecimento organizacional, o paradigma interpretativo considera que os indivíduos produzem não apenas trabalho ou conhecimento que lhe é inerente, mas, também, relações sociais, identidades, autoimagens. A ação de conhecer é sempre situada na esfera da interação social realizada na comunidade organizacional (GHERARDI, 2006), sendo impossível "não conhecer" (ELKJAER, 2003). Conhecer é uma ação social de construção de significados baseada em experiências subjetivas naquele contexto.

Para acessar essa dimensão, o método qualitativo adotado foi o GTM. Tal escolha se justifica, em primeiro lugar, porque é possível estender a afinidade filosófica do pragmatismo (PEIRCE, 1998; DEWEY, 1938, 1998) ao objeto desta pesquisa: a concepção do conhecimento organizacional como ação; como processo que se estabelece no indivíduo e entre indivíduos no ato de trabalhar (GHERARDI, 2006); como questionamento que é parte do próprio processo de conhecer (ELKJAER, 2003). Em segundo, o pragmatismo de Peirce (1998) traz a lógica abdutiva, comum tanto ao GTM (BRYANT e CHARMAZ, 2007) quanto ao conhecimento construído e aplicado na ação organizacional por meio de narrativas (BARTEL e GARUD, 2003). Nessa lógica, tanto o método de análise quanto o conhecimento envolvem a utilização de regras, normas, modelos mentais, valores e crenças constitutivos dos quadros de referência existentes naquele contexto, assim como a apreensão dos resultados obtidos em eventos para inferir os casos, situações, conhecimentos, comportamentos válidos naquele ambiente (BARTEL e GARUD, 2003). Em terceiro, o GTM é um método explícito para analisar processos (BRYANT e CHARMAZ, 2007; CHARMAZ, 2006; GLASER e STRAUSS, 2006). Um processo consiste em uma sequência temporal contínua de desdobramentos (eventos) que tem marcos identificáveis de começo e fim, e de referência no meio. Essas sequências temporais são ligadas por processos e levam a uma mudança de um estágio a outro nos indivíduos (CHARMAZ, 2006). Na pesquisa, o marco temporal foi representado pela situação em que o indivíduo considerou seu conhecimento valorado ou não no contexto do trabalho.

O objetivo deste estudo foi identificar os processos e mecanismos adotados pelos indivíduos para a valoração do conhecimento na organização. Quanto 
à amostragem teórica, selecionou-se o grupo de sujeitos, por meio do processo de snowball, a partir de uma área específica de atuação profissional (GLASER e STRAUSS, 2006): profissionais de RH; aqueles por quem, em princípio, circulam rotinas, aspectos culturais e estruturais, estratégias, competências, práticas de treinamento e desenvolvimento e fluxo de conhecimento da organização. Visando atender aos requisitos diversidade e variedade do GTM para comparação entre modos e processos (BRYANT e CHARMAZ, 2007; GLASER e STRAUSS, 2006), buscaram-se profissionais em 13 empresas, atuantes em nove setores. O Quadro 1 sintetiza a amostragem teórica, embora os dados de perfil dos 16 entrevistados, com gênero, formação, tempo de experiência profissional, tipo de indústria e cargo, tenham sido omitidos por questão de espaço.

Realizaram-se entrevistas em profundidade, baseadas em roteiro semiestruturado, com duração média de uma hora, no local de trabalho dos entrevistados, gravadas e transcritas para análise de codificação e de categorização com auxílio do software Atlas Ti (MILlER e SALKIND, 2002). O roteiro foi composto de três partes: a) o que é conhecimento para o indivíduo; b) como ele o valora e quais significados são atribuídos aos seus conhecimentos, exemplificando; c) quais conhecimentos a organização valora e como.

Conforme prescreve o GTM, realizaram-se, recursivamente, a coleta e a análise dos dados, aprofundando-se, sistematicamente, os questionamentos a cada nova entrevista ou reentrevista. Com esse pro-

\section{Quadro 1 - Amostragem teórica}

\begin{tabular}{|c|c|}
\hline $\begin{array}{l}\text { Critérios de } \\
\text { variedade }\end{array}$ & Perfil e número de entrevistados \\
\hline $\begin{array}{l}\text { Tempo de atua- } \\
\text { ção profissional }\end{array}$ & $\begin{array}{l}\text { até } 10 \text { anos: } 6 \\
\text { de } 11 \text { a } 20 \text { anos: } 5 \\
\text { acima de } 21 \text { anos: } 5\end{array}$ \\
\hline Posição & $\begin{array}{l}\text { início de carreira/coordenação: } 3 \\
\text { gerência intermediária: } 7 \\
\text { alta gerência/diretoria: } 6\end{array}$ \\
\hline Tipo de empresa & $\begin{array}{l}\text { pública ou mista: } 4 \\
\text { privada nacional: } 5 \\
\text { privada multinacional: } 7\end{array}$ \\
\hline Formação & $\begin{array}{l}\text { Administração: } 4 \\
\text { Psicologia: } 6 \\
\text { Economia, Engenharia, Informática e outros: } 6\end{array}$ \\
\hline
\end{tabular}

cedimento, buscou-se refinar os achados encontrados indutivamente (BRYANT e CHARMAZ, 2007; GLASER e STRAUSS, 2006). As entrevistas foram inicialmente codificadas por trechos in-vivo, de acordo com suas propriedades de conteúdo. Em seguida, agruparam-se esses trechos em códigos de primeira ordem, que foram consolidados em categorias, as quais, depois de aglutinadas e refinadas, deram origem aos seis mecanismos identificados pelas pesquisadoras. O processo por meio do qual os indivíduos valoram os conhecimentos emergiu do processo de identificação (somos iguais)/não identificação (somos diferentes) com a IO, com base em três dimensões: ação, justificativa e comportamento. O Quadro 2 apresenta $O$ resultado encontrado.

Julgou-se que a saturação teórica tenha sido atingida diante de três fatos: a) não se adicionou nova codificação às últimas quatro narrativas; b) a inserção dos sujeitos nas pré-categorias existentes deu-se com facilidade; c) não se evidenciaram novas categorias emergentes com novos dados coletados. Os dados foram rechecados em relação às categorias para assegurar validade interna. O referencial teórico referente à identificação e à IO, e suas relações com valoração do conhecimento, foi construído após a análise inicial dos dados emergentes do campo, na etapa de agrupamento dos códigos de primeira ordem em categorias.

\section{ANÁLISE DOS DADOS E ACHADOS EMERGENTES DO CAMPO}

Valor do conhecimento para o indivíduo: significação e relação entre o valor do conhecimento e ser (being)

Identificou-se uma forte ligação entre o valor que o indivíduo atribui ao seu conhecimento e 'ser' o indivíduo. Esse achado foi constatado nas falas, especialmente nos momentos em que os conhecimentos aos quais os indivíduos atribuíam maior valor não foram utilizados pela organização. Esses momentos são caracterizados pela organização, representada pelas chefias: a) solicitando que o indivíduo faça um projeto mais básico ("fazer menos"), b) não aprovando um projeto desenvolvido pelo indivíduo; ou c) não o escolhendo para algum projeto ou posição para o qual o indivíduo considerava que possuía os conhecimentos necessários.

Para a maioria dos entrevistados, essas situações foram consideradas momentos de "frustração 
pessoal", "falta de reconhecimento" e "desvalorização pessoal e profissional". Entendeu-se que os indivíduos se sentiram pessoalmente atingidos e desprestigiados ao não terem seus conhecimentos aplicados. Traçou-se um paralelo com Elkjaer (2003), que argumenta que o conhecer (knowing) e o ser são indissociáveis, senão a mesma coisa. Nesse caso, o valor atribuído ao conhecimento que o indivíduo possui valora o que o indivíduo é, tanto pessoal como profissionalmente.

O fato de não conseguir colocar seu conhecimento em prática na organização afeta pessoalmente o indivíduo, gerando reações e comportamentos tais como: mecanismos de sobrevivência para permanência naquele ambiente (entrevistado 5); planejamento para saída (entrevistados 1 e 3); ou ruptura total com a organização (entrevistados 2 e 3 ).

\footnotetext{
Eu estruturei e implantei toda a área de Centro de Serviços Compartilhados lá na [organização]. Como eu era gerente... eu tinha uma expectativa de vir a ser a gerente executiva daquele Centro... eu fui chamada, e ele [diretor de RH] falou: "Não, agora você vai ficar no Centro de Serviços Compartilhados como gerente...", mesmo eu tendo a estrutura de conhecimento para ser gerente executiva. Então foi a primeira frustração. Não fui eu a escolhida! Por mais que o outro tivesse motivos... [...] Uma não escolha pra um trabalho já realizado e implantado por mim! [...] Eu me senti regredindo [profissionalmente], um retorno a um estágio que eu já tinha superado, vivendo uma situação de não confiança [pessoal]... (entrevistada 3).
}

Alguns entrevistados (4, 9, 12, 16), apesar de perceber e reconhecer que não possuíam seus conhecimentos totalmente utilizados pela organização, encontraram justificativas para lidar com a frustração e a dissonância cognitiva decorrente da falta de reconhecimento institucional. Nesses casos, recorreram a explicações tais como: o conhecimento coletivo apenas se utiliza de parte dos conhecimentos individuais; estão na organização para indicar o que deve ser feito, mas a escolha pertence a outros, geralmente à alta gestão; podem apenas influenciar. Outros assumem o discurso corporativo $(10,13)$, na linha de que a organização é muito clara em seus modelos e cabe aos membros organizacionais encontrar-se no modelo organizacional.

Três entrevistadas $(6,11,15)$, porém, não encontraram esses momentos de não valorização ou não aplicação de seus conhecimentos em suas carreiras, sendo duas pertencentes ao grupo com menor tempo de experiência profissional. Elas possuem forte identificação com as organizações onde trabalham e expressam afinidade entre o que elas são e os conhecimentos valorados pela organização (na interpretação delas).

\footnotetext{
Eu não acho que os sete anos de banco tenham me influenciado, moldado essa coisa do "Eu preciso ter a base instrumental, formal" que eu falei. Porque eu sempre estudei muito, então eu acho que isso é uma coisa minha, eu sou assim. Tem talvez valores de família. Mas certamente o banco pode ter reforçado isso no sentido do que ele valoriza. [...] Faz parte do DNA da casa analisar. (entrevistada 11).
}

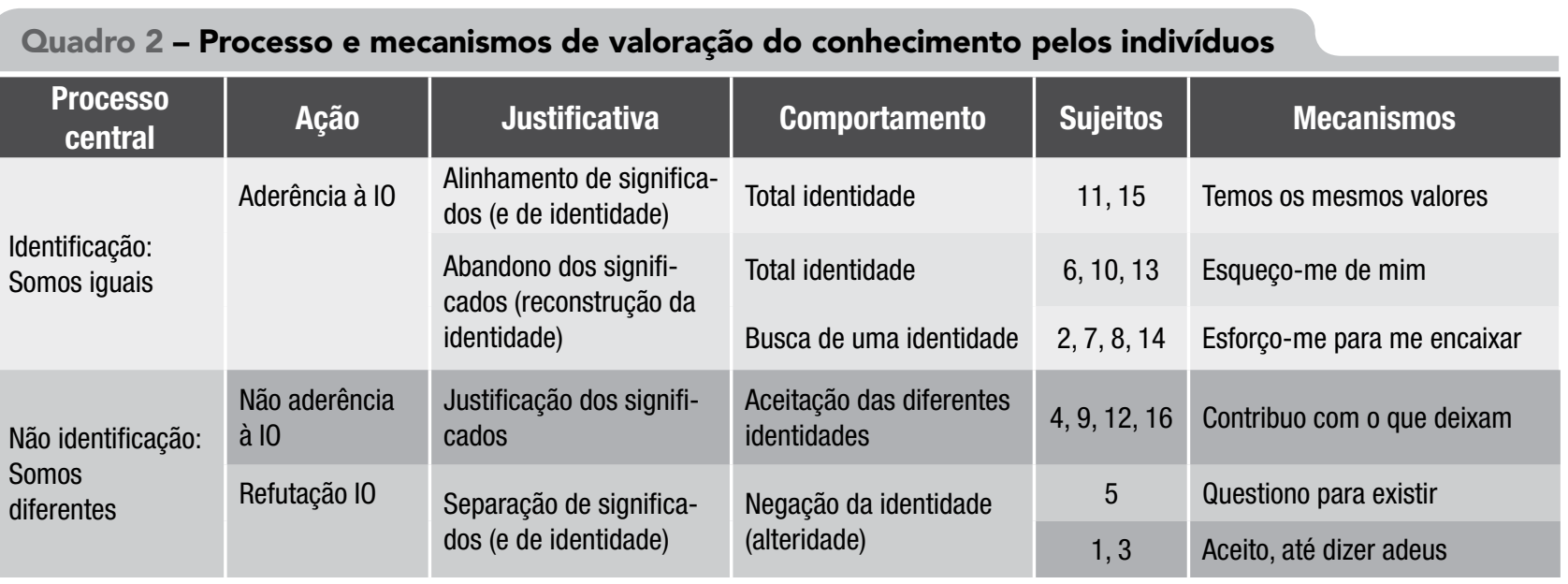




\section{Valor do conhecimento para a organização: sensemaking, identificação e reconstrução das identidades}

Ao elencar os componentes de seu conjunto de conhecimentos, os indivíduos definiram os que representavam maior valor de importância para eles. Nesse processo de autoatribuição, o conhecimento valorado adquiriu uma série de significações, de representações que dão sentido e explicam a sua utilidade (CORLEY e GIOIA, 2003). Essas significações parecem explicar por que ou como os indivíduos aplicam o conhecimento nas suas atividades, no seu trabalho: porque "permite o desafio", o "sucesso"; "possibilita o questionamento", a "reflexão", a "análise"; "possibilita propor novas soluções"; "traz inovação"; "permite criar"; "possibilita transitar na diversidade"; entre outras.

Identificou-se que essa significação está relacionada a uma identidade - o conhecimento de valor que o indivíduo possui ou como o utiliza e advém de percepções diversas do entrevistado não ancoradas em qualquer contexto ou referente em particular. À medida que contextos (uso do conhecimento do trabalho) ou referentes (pares, chefia, membros organizacionais) são incluídos na entrevista, as significações alteram-se, assim como a identidade é ajustada ou reconstruída.

Entretanto, no decorrer da entrevista, quando questionados acerca de quais conhecimentos a organização valorava, todos os entrevistados, sem exceção, iniciaram suas respostas/narrativas explicando como é a organização (identidade central) e como ela se importa/quer/acredita/faz/pode (conteúdo da identidade) (ASHFORTH e outros, 2008). Todos sentiram a necessidade de apresentar quem era a organização - modelo de gestão, estrutura organizacional, características da cultura, interveniências políticas, forma de atuar, valores organizacionais - antes de responder como ou quais conhecimentos eram valorados. Entendeu-se que esse momento foi necessário para o indivíduo reconstruir a narrativa de identificação com a organização, conforme a relação entre os níveis da identidade (ASHFORTH e outros, 2008).

Nesse momento, a organização, por intermédio das rotinas e modelos estabelecidos, das formas de atuar e das interveniências da alta gestão, surgiu como "o outro" que parece conduzir as diretrizes organizacionais a serem seguidas, assim como os conhecimentos a serem valorados pelos indivíduos. Sugere-se que a incorporação de conhecimentos na construção social dos sujeitos acompanha as diretrizes organiza- cionais, na medida em que os sujeitos consideram, em suas articulações, tanto os atributos de importância ao conhecimento formalmente estabelecidos quanto os modelos organizacionais por meio dos quais os conhecimentos de valor serão absorvidos.

Em decorrência, surgiu o processo de identificação ou não identificação entre os entrevistados para com a organização, ou seja, o organizationally based identity: nível individual da identidade coletiva (CORLEY e outros, 2006). Muitas das significações atribuídas ao valor do conhecimento, no início das entrevistas, foram abandonadas pelos entrevistados; surgiram novas significações, assim como apareceram diversos mecanismos visando alinhar, encaixar, justificar, diferenciar ou negar a identidade entre o indivíduo e as diretrizes organizacionais. As identidades foram reconstruídas (ajustadas, justificadas ou recriadas), por meio do discurso (WEICK, 1995), em grande parte dos casos. Essas categorias serão detalhadas no tópico seguinte.

Gao e Riley (2010) propunham que as identidades sociais atuariam no processo de valoração de conhecimento. Nas entrevistas, emergiram autocategorizações de múltiplas identidades, baseadas nas relações entre os grupos na organização (novos-antigos; generalista-especialista; gerente-não gerente, entre outras), e não categorias sociais fixas (por exemplo, a categoria profissional proposta em Gao e Riley (2010)). Os grupos de identidades autocategorizadas também pareciam direcionados pela própria organização, na sua forma de atribuir importância a determinados grupos e seus conhecimentos em detrimento de outros, achado similar ao de Antonacopoulou (2006) e Harman (2012). Uma discussão acerca das identidades autocategorizadas ficou fora do escopo deste artigo.

\section{Categorização dos mecanismos de identificação para a valoração do conhecimento}

Conforme já mencionado, a organização surgiu como o principal referente com o qual o indivíduo se identifica e reconstrói sua identidade para fazer sentido do valor de seu conhecimento, e de si mesmo, no ambiente organizacional. Os processos de trabalho de identidade e de identificação são aqueles que os indivíduos utilizam para a valoração e o reconhecimento dos seus conhecimentos no ambiente organizacional. Identificaram-se seis mecanismos, sendo três relacio- 
nados à identificação e três à não identificação com a organização, detalhados a seguir.

\section{Temos os mesmos valores}

Nesse mecanismo, os indivíduos apresentaram total identificação com a organização, aderindo à IO de tal modo que há um alinhamento das suas identidades pessoais com a da organização. Falar da organização é falar de si mesmo, falar dos conhecimentos valorados pela organização é falar dos seus conhecimentos, e também da sua forma de ser. Porém, cabe ressaltar que tais identidades individuais não foram ajustadas ou reconstruídas no decorrer da entrevista, ou seja, os entrevistados iniciaram a conversa falando dos conhecimentos valorados e prosseguiram na entrevista descrevendo e narrando sobre uma organização que valorava exatamente o mesmo que eles. Um exemplo encontra-se na fala da entrevistada 15.

Eu acho que não mudei. Como característica central... Eu tinha essa energia, eu brigava por aquilo que eu queria, que eu acreditava, eu era supercrítica... Então, eu acho que eu tinha muito todas essas características que a organização queria. [...] Eu devia ter algumas características e conhecimentos e, para ser valorizada, eu também fui me adaptando. E a gente vai, sem perceber, se moldando. Então, eu acho que quem fica nesse tipo de organização, em qualquer organização, tem um processo de identificação. [...] E você quer isso...

\section{Esqueço-me de mim}

Houve total identificação dos indivíduos com a organização, com adesão à IO, nessa categoria. Entretanto, essa aderência foi processada pelos indivíduos por meio do abandono do seu discurso inicial acerca dos conhecimentos valorados e sua significação, dando lugar a uma nova identidade, em acordo com os conhecimentos valorados pela organização. Quando a organização entra na entrevista, o discurso organizacional substitui claramente a fala do indivíduo. As identidades são ajustadas para caber nos conhecimentos valorados pela organização, a ponto de alguns entrevistados contradizerem Colocações iniciais sobre o valor do conhecimento e suas significações.

Um caso emblemático é da entrevistada 6. O conhecimento, para ela, significava inicialmente a compreensão da diversidade, e essa compreensão era apresentada como um valor pessoal que permitia a escolha profissional dela:

\footnotetext{
Isso também já diz muito de como eu sou. [...] para trabalhar com a temática de Saúde e Segurança, a gente precisa entender diferentes culturas. Tem que estar aberto a diferentes cenários. O [colégio] me ajudou na minha formação e a psicologia também. [...] Isso me ajudou muito a chegar aqui sem preconceitos, aceitando a diversidade. Com a cabeça aberta. [...] E eu escolhi trabalhar nessa área [Saúde e Segurança] porque eu me identifico com esse tipo de trabalho. Trabalho de fomento dos valores que são os valores que eu acredito.
}

Quando, porém, os conhecimentos valorizados pela organização entram na conversa, a entrevistada fala do status e glamour possibilitados pela imagem que advém da área onde atua:

\begin{abstract}
A gente é uma empresa muito técnica, que faz o que ninguém no Brasil faz. Então, o conhecimento dentro da [organização] é negócio. É diferencial estratégico. É um dos nossos diferenciais competitivos. [...] os profissionais que estão aqui dentro, e o que a gente faz aqui não é estudado em universidade. As pessoas aprendem na prática. [...] Então, hoje a [área da organização] é a área mais glamourosa. É onde as pessoas querem ir! É onde tem mais dinheiro investido, onde a estrutura é mais bonita. Para você ter uma ideia, todas as áreas da [organização] mudaram o nome. A gente não é uma Diretoria. Eu não vou me apresentar como "Ah, eu sou da diretoria IDT". Eu até sou, mas ninguém sabe. Eu me apresento falando "Eu sou da [área da organização]". Tem mais dinheiro em treinamento dentro da [área da organização] do que muitos municípios têm em saúde e educação, por exemplo. Então, a gente tem muito dinheiro, a gente faz as coisas muito bem. A gente é reconhecida no mercado como uma área de benchmarking. Então hoje, dentro do RH, a [área da organização] é a área mais valorizada!
\end{abstract}

\section{Esforço-me para me encaixar}

Os entrevistados possuem identificação com a organização, com adesão à IO. Porém, esse processo é feito à custa de um esforço ativo do indivíduo em buscar o encaixe da sua identidade individual à organiza- 
cional. Os entrevistados demonstram a dificuldade e certo desconforto em procurar ser e ter o conhecimento que a organização julga importante, e que não é aquele que os distingue, tampouco aquele que eles valoram. Os indivíduos parecem saber claramente o que a organização valora. No entanto, tal percepção não foi expressa diretamente a eles por parte das organizações: eles tiveram de descobrir vivendo e trabalhando naquele ambiente. Em todos os casos, o processo parece doloroso, de tentativa e erro. Nas narrativas, há um pouco de angústia pela pressão em ser outra coisa, mas também um otimismo, geralmente justificado pelo desenvolvimento e aprendizagem de novas formas.

Embora nas entrevistas tenha transparecido ser um mecanismo consciente, analisou-se que a conversa ocasionou um momento de reflexão sobre um processo de busca e de adequação realizado de maneira inconsciente, mas sentida. Uma fala representativa dessa categoria é a da entrevistada 13.

\begin{abstract}
Aqui na [organização], às vezes, eu tenho impressão de que eu poderia usar os meus conhecimentos de forma diferente, mas o modelo não permite. Então, não é que o meu conhecimento não seja reconhecido... Mas eu acho que eu, talvez, esteja tentando aprender a tirar um outro melhor de mim. Não o que eu já sabia. "Ok. Esse é o melhor de mim. Ok, mas aqui dentro isso não é o melhor. Então, como eu vou dar o melhor de mim agora neste modelo?". Você acaba até se desenvolvendo, porque você tem que encontrar um outro modelo de trabalho. Um outro caminho pra usar aquele seu valor.
\end{abstract}

\section{Contribuo com o que deixam}

Nesse mecanismo, os entrevistados não possuem identificação com a organização e não aderem à IO. Eles enxergam a organização na sua complexidade, com seus pontos negativos e positivos, se veem como diferentes da organização: os conhecimentos valorados são distintos, a forma de atribuir valor também. Desse modo, eles aceitam as diferenças e convivem na organização. Os conhecimentos valorados e suas significações são mantidos com coerência no decorrer da conversa. As narrativas giram em torno da justificação do uso ou não uso dos conhecimentos considerados importantes naquele ambiente organizacional. Os entrevistados discorrem sobre as limitações e barreiras organizacionais na utilização de seus conhecimentos individuais de modo mais amplo e complementar, e também a compreensão de que o conhecimento coletivo não abarcará todo o conhecimento de que o indivíduo dispõe. A narrativa do entrevistado 9 demonstra isso:

\footnotetext{
O conhecimento que a organização tem é mais que a soma desses conhecimentos pessoais. Não é uma soma aritmética do que cada um é. [...] É a conjunção do conhecimento das pessoas que aqui trabalham, mas elas juntas formam uma outra dinâmica. Essa dinâmica do conhecimento da empresa é muito guiada, orientada pelo chefe da empresa, pelo líder da empresa, pelo presidente, pelo fundador... Ele tem uma influência maior sobre isso. Ele vai dar o contorno a essa soma desses conhecimentos, porque ele vai valorizar um tipo de conhecimento a outro tipo de conhecimento.
}

Esses entrevistados definem seu papel como de influenciadores e negociadores com a organização, contribuindo na medida em que ela permite. Trata-se de indivíduos do grupo com maior experiência e maturidade profissional, ocupantes de cargos elevados.

\footnotetext{
Ele é o dono da empresa. Essa é a empresa dele. [...] Eu não vou dizer que essa fórmula é errada, mas, sim, que é a fórmula certa para ele. Essa fórmula não sobreviveria se isso aqui fosse um banco. No mercado onde ele está, ele perde muitas coisas com isso, perde agilidade, mas ganha outras coisas. E principalmente ganha conforto. [...] Então você pode melhorar, contribuir... Eu sei respeitar isso. Eu vim para um "projeto" que quem me contratou é que determina. Lógico que vou colocar um pouco de mim, tento influenciar, negociar, tento contribuir com o meu conhecimento para formação do conhecimento deles...
}

\section{Questiono para existir}

Nesse mecanismo e no seguinte, a não identificação com a organização é forte o suficiente a ponto de o indivíduo refutar a IO. Os entrevistados separam os significados do valor do conhecimento para eles como indivíduos e o significado do valor do conhecimento como membros organizacionais; como se fossem de domínios, de naturezas distintas, traduzidos nas suas falas.

O presente mecanismo é representado por uma única entrevistada (5). Sabedora da falta de identifi- 
cação com a organização, colocou-se na posição de enfrentamento, resistente e questionadora das ações e valorações da organização. Analisou-se ser a forma encontrada por ela de se fazer ouvida em seus conhecimentos no novo ambiente, com o objetivo de se sentir respeitada.

\footnotetext{
Você se frustra e na verdade você está dentro de uma organização. De alguma forma você tem que ter uma consonância com isso, porque o dinheiro não é meu. Eu não sou acionista, não sou a dona da companhia. Eu tenho que trabalhar para ela. Então, muitas vezes, eu não concordo. Se não for uma coisa que me agrida tanto, eu relevo. O quanto mais a gente conseguir influenciar fazendo um bom trabalho que seja útil, que seja relevante. Relevante para o negócio. Eu trabalho para isso. [...] Então, eu falo que eu não quero uma grade de treinamento [embora seja isto que a organização peça]. Isso, para mim, qualquer um faz. Você vai executar esse plano de treinamento, mas vai ser útil? As pessoas vão usar? Isso vai ser relevante, vai alavancar o negócio? [...] Então eu estou botando muito a postura questionadora aqui.
}

\section{Aceito, até dizer adeus}

Do mesmo modo que no mecanismo anterior, há refutação da IO. Os entrevistados não se identificam com a organização, mas seu mecanismo é a aceitação, até ter uma opção de saída. Os conhecimentos valorados pela organização são de domínio diferente do individual. No caso da entrevistada 3, há uma separação total de valores, ela sempre mencionava o dualismo "no trabalho" e "na minha vida pessoal".

No caso do entrevistado 1 , até há bem pouco tempo, ele não percebia a cisão entre as esferas trabalho e pessoal; vivia em adesão à identidade das organizações por onde havia passado, em uma lógica em que o único conhecimento de valor era de cunho utilitário, e a narrativa na entrevista refletia esse fato (o total esquecimento de si mesmo).

Porém, ao relatar sobre os conhecimentos valorados na organização de consultoria onde trabalhava, o entrevistado muda a narrativa completamente e, de modo inesperado, "desabafa" que está se questionando sobre a forma de trabalhar, a vida no trabalho. Todos os conhecimentos valorados por ele, em adesão às organizações até aquele momento, deixam de ter relevância.

\begin{abstract}
Em termos de conhecimento mesmo, tecnicamente falando, eu me sinto mais forte. Porque, na medida em que você é submetido a uma série de experiências, que você é colocado em situações que numa empresa normal, ou numa situação normal, você não seria colocado, e você tem que se virar, isso, de alguma maneira, te traz amadurecimento. Te empurra. Não tem jeito. Esses dois anos e meio que eu tenho de [consultoria] foram muito mais intensos do que todos os outros anos que eu tive, em termos de aprendizado... Mas, por outro lado... me fez balançar. Entende? Um pouco pelo fato de ser a [organização de consultoria], um pouco pelo momento de vida. De refletir a respeito do que quero pra mim, do que eu quero da minha vida.
\end{abstract}

\section{DISCUSSÃO dOS RESULTADOS}

O objetivo desta pesquisa foi investigar os processos e mecanismos adotados pelos indivíduos para a valoração do conhecimento na organização. Os resultados sugerem que o processo de identificação dos indivíduos com a IO (ASHFORTH e outros, 2008) ocupa um lugar central na valoração do conhecimento. A organização, por intermédio da chefia, da alta gerência, ou das rotinas e modelos estabelecidos, surgiu como "o outro" que parece conduzir as diretrizes a serem seguidas, em última instância, os conhecimentos a serem valorados pelos indivíduos. Há uma construção social, envolvendo os sujeitos, que faz as diretrizes organizacionais predominarem.

A organização, centrada na alta gestão e nas rotinas e modelos organizacionais, configurada como uma entidade abstrata, emergiu mais fortemente do que os pares ou outros membros organizacionais. Ela surgiu como o principal referente com quem o indivíduo precisa buscar (ou não) se identificar. Por meio das narrativas, verificamos o processo de reconstrução das identidades e os mecanismos de identificação e não identificação dos indivíduos para com a organização, a fim de fazer sentido do valor de seu conhecimento (WEICK, 1995) e de si mesmos (ELKJAER, 2003; HARMAN, 2012).

Desse modo, os indivíduos expressaram, nas narrativas, mecanismos de afirmação, adequação ou reconstrução de suas identidades, a fim de gerar, justificar ou negar identificação com a organização. Categorizamos tais mecanismos em seis tipos de iden- 
tificação ligados a modos de construção da identidade, a partir da valoração do conhecimento: Temos os mesmos valores; Esqueço-me de mim; Esforço-me para me encaixar; Contribuo com o que deixam; Questiono para existir; Aceito, até dizer adeus. O trabalho de construção identitária e os mecanismos citados parecem auxiliar os membros na sua permanência ou para a saída da organização.

Em decorrência dos aspectos mencionados, sugere-se que a incorporação de conhecimentos na construção social dos sujeitos, resultantes da ação organizacional (knowing) (BROWN e DUGUID, 2001; GHERARDI, 2006), acompanha as diretrizes organizacionais. Esse ponto de vista pode ser sustentando com base na percepção de que os sujeitos consideram, em suas articulações, tanto os atributos de importância formalmente estabelecidos ao conhecimento quanto os modelos organizacionais pelos quais os conhecimentos de valor poderão ser absorvidos. Julga-se importante destacar que esses achados são similares aos de Antonacopoulou (2006). Ademais, foi identificado que, a exemplo de o conhecimento ser o indivíduo (ELKJAER, 2003; HARMAN, 2012), a valoração ou desvalorização do conhecimento impacta no que o indivíduo é pessoalmente, na sua valoração ou não valoração pessoal.

Quanto aos pares e demais membros organizacionais, nota-se que o processo de negociação entre eles está presente, fazendo parte do trabalhar e conhecer (BROWN e DUGUID, 2001; GHERARDI, 2006). Porém, esse processo pareceu ser muito tácito e sutil para merecer uma atenção maior por parte dos entrevistados (conforme os achados de CORLEY e GIOIA, 2003), em comparação com as diretrizes organizacionais. Esta pesquisa sugere que há uma construção coletiva de sentido acerca do que é trabalhar, conhecer e valorar nas organizações (WEICK, 1995). Essa construção social evidenciou-se quando os indivíduos foram especificamente questionados acerca de pares, equipes e pessoas envolvidas nos exemplos de situações de conhecimento valorado, narradas pelos entrevistados. Os contextos trazidos pelos entrevistados diziam respeito, basicamente, à participação dos membros em reuniões e projetos, quase sempre de modo coadjuvante ou trivial, e comumente em situações formalizadas pela organização.

No estudo, a predominância das diretrizes organizacionais como referente destacou-se na construção social dos sujeitos. Trata-se de como a realidade é interpretada e significada pelos indivíduos para traba- lhar naquele ambiente (WEICK, 1995). De todo modo, verificou-se certo efeito reducionista e limitante que se processa nos indivíduos quanto à utilização de seus conhecimentos no trabalho, em consonância com os estudos de Antonacopoulou (2006), Contu e Willmott (2003), Nag e outros (2007), Oborn e Dawson (2010), Harman (2012), que trataram dessa questão sob a ótica de poder. Pode-se inferir que, dificilmente, novos conhecimentos possam surgir, se estabelecer ou ser incorporados nas práticas organizacionais, caso não estejam alinhados àqueles conhecimentos considerados importantes pela organização, alta gestão ou grupos dominantes na organização.

Em decorrência dos achados apresentados, discutimos até que ponto o paradigma de comando-controle ainda permanece presente nas organizações, nos dias de hoje. De modo mais sutil, o comando-controle estaria sendo exercido na forma da organização como o referente do modelo de identidade para os indivíduos? Esta pesquisa parece indicar que o modelo de comando vertical ainda prevalece sobre a interação horizontal, tornando difícil o estabelecimento de conhecimento emergente entre os membros organizacionais. Entendemos que essas discussões são relevantes para aprofundamento, em função das implicações para a gestão empresarial no contexto pós-moderno globalizado.

\section{CONCLUSÃO, LIMITAÇÕES, CONTRIBUIÇÃO E SUGESTÕES PARA PESQUISAS FUTURAS}

O presente estudo identificou os processos de identificação e IO como os meios pelos quais os indivíduos valoram o conhecimento nas organizações e, com base neles, propôs seis mecanismos utilizados pelos membros organizacionais. Sugerimos também que, em face da emergência da organização como referente, a incorporação dos conhecimentos se daria verticalmente pelo que é valorado por esse referente, e não tanto por meio dos pares, horizontalmente.

Os achados deste trabalho apresentam relevância para os profissionais e organizações, especialmente para a alta gestão, ao sugerir a presença do enfoque ainda tradicional de comando-controle existente nas organizações, que limita a criatividade e o compartilhamento de conhecimento. Em um ambiente pós-moderno, que exige contínua inovação em face dos 
desafios competitivos, evidenciamos que as organizações podem deixar de acessar experiências, valores, vivências e relacionamentos de conhecimento dos indivíduos, simplesmente por ignorar ou não valorar outras formas de ação organizacional. Deve-se levar em consideração o possível efeito limitante e reducionista da capacidade dos indivíduos de contribuírem com seus conhecimentos na ação organizacional, em função das escolhas de valoração de conhecimento feitas pela alta gestão das organizações. Relevante para a academia, trata-se do papel de disseminar uma visão mais ampla e abrangente do que é conhecimento, compreendida no próprio ato de trabalhar, participar, conhecer e contribuir na organização.

Como sugestão a pesquisas futuras, cabe ampliá-las a outras categorias profissionais, além de RH. Emergiram também questões adicionais. A primeira relaciona-se às autocategorizações em múltiplas identidades sociais, baseadas nas relações entre os grupos na organização, que parecem ter um papel na valoração do conhecimento, uma vez que contribuem na separação entre conhecimentos considerados mais e menos importantes, em função do grupo que a organização valora. A segunda diz respeito às perspectivas bastante estreitas quanto ao que constitui conhecimento para os profissionais de RH: constatamos visões ainda tradicionais do conhecimento, como educação formal e experiência profissional, ignorando outras dimensões do conhecimento, como relação, vivência e valores que ocorrem na ação coletiva de trabalhar.

\section{NOTA DOS AUTORES}

Agradecemos aos revisores da $R A E$, que, por meio de suas oportunas e enriquecedoras contribuições ao artigo, iluminaram aspectos relevantes do estudo e na construção do conhecimento compartilhado.

\section{NOTA DA REDAÇÃO}

Este artigo participou do VII Encontro da Divisão de Estudos Organizacionais (ENEO), realizado em 2012 pelaAssociação Nacional de Pós-Graduação e Pesquisa em Administração (Anpad).

\section{REFERÊNCIAS}

ANTONACOPOULOU, E. P. The relationship between individual and organizational learning: new evidence from managerial learning practices. Management Learning, v. 37, n. 4, p. 455-473, 2006.

ASHFORTH, B. E; HARRISON, S. H; CORLEY, K. G. Identification in organizations: an examination of four fundamental questions. Journal of Management, v. 34, n. 3, p. 325-374, 2008.

BARNEY, J. Firm resources and sustained competitive advantage. Journal of Management, v. 17, n. 1, p. 99-120, 1991.

BARTEL, C. A; GARUD, R. Narrative knowledge in action: adaptive abduction as a mechanism for knowledge creation and exchange in organizations. In: EASTERBY-SMITH, M; LYLES, M. The Blackwell handbook of organizational learning and knowledge management. Oxford: Blackwell, 2003. p. 324-342.

BROWN, A. D; STARKEY, K. Organizational identity and learning: a psychodynamic perspective. Academy of Management Review, v. 25, n. 1, p. 102-120, 2000.

BROWN, J. S; DUGUID, P. Knowledge and organization: a social-practice perspective. Organization Science, v. 12, n. 2, p. 198-213, 2001.

BRYANT, A; CHARMAZ, K The Sage handbook of grounded theory. Thousand Oaks: Sage, 2007.

BURREL, G; MORGAN, G. Sociological paradigms and organizational analysis. Vermont: Ashgate, 2003.

CHARMAZ, K. Constructing grounded theory: a practical guide through qualitative analysis. Thousand Oaks: Sage, 2006.

CONTU, A; WILLMOTT, H. Re-embedding situatedness: the importance of power relations in learning theory. Organization Science, v. 14, n. 3, p. 283-296, 2003.

COOK, S. D. N; BROWN, J. S. Bridging epistemologies: the generative dance between organizational knowledge and organizational knowing. Organization Science, v. 10, n. 4, p. 381-400, 1999.

COOK, S. D. N; YANOW, D. Culture and organizational learning. Journal of Management Inquiry, v. 2, n. 4, p. 373-390, 1993.

CORLEY, K. G; GIOIA, D. A. Semantic learning as change 
enabler: Relating organizational identity and organizational learning. In: EASTERBY-SMITH, M; LYLES, M. The Blackwell handbook of organizational learning and knowledge management. Oxford: Blackwell, 2003. p. 621-636.

CORLEY, K. G; HARQUAIL, C. V; PRATT, R; GLYNN, M. A; FIOL, C. M; HATCH, M. J. Guiding organizational identity trough aged adolescence. Journal of Management Inquiry, v. 15, n. 2, p. 85-99, 2006.

DEWEY, J. The essential Dewey: Pragmatism, education, democracy. Bloomington: Indiana University Press, 1998.

DEWEY, J. Logic: The theory of inquiry. New York: Holt, Rinehart and Winston, 1938.

DUTTON, J. E; DUKERICH, J. M; HARQUAIL, C. V. Organizational images and member identification. Administrative Science Quarterly, v. 39, n. 2, p. 239-263, 1994.

ELKJAER, B. Social learning theory: learning as participation in social processes. In: EASTERBY-SMITH, M; LYLES, M. The Blackwell handbook of organizational learning and knowledge management. Oxford: Blackwell, 2003. p. 38-53.

GAO, Y; RILEY, M. Knowledge and identity. International Journal of Management Reviews, v. 12, n. 3, p. 317334, 2010.

GHERARDI, S. Organizational knowledge: the texture of workplace learning. Malden: Blackwell, 2006.

GLASER, B. G; STRAUSS, A. L. The discovery of grounded theory. New Brunswick: Aldine Transaction, 2006.

GRANT, R. M. Toward a knowledge-based theory of the firm. Strategic Management Journal, v. 17, winter, p. 109122, 1996.

HANDLEY, K; CLARK, T; FINCHAM, R; STURDY, A. Researching situated learning: participation, identity and practices in client-consultant relationships. Management Learning, v. 38, n. 2, p. 173-191, 2007.

HARMAN, K. Everyday learning in a public sector workplace: the embodiment of managerial discourses. Management Learning, v. 43, n. 3, p. 275-289, 2012.

HARQUAIL, C; KING, T. Organizational identity and embodied cognition. Proceedings of The Academy of Mana- gement Congress, The Academy of Management, Seattle, August, 2003.

HEDBERG, B; WOLFF, R. Organizing, learning, and strategizing. In: DIERKES, M: NONAKA, I. Handbook of organizational learning \& knowledge. Oxford: Oxford University Press, 2001. p. 535-556.

KANE, A. A. Unlocking knowledge transfer potential: knowledge demonstrability and superordinate social identity. Organization Science, v. 21, n. 3, p. 643-660, 2010.

LAVE, J; WENGER, E. Situated learning: legitimate peripheral participation. Cambridge: Cambridge University, 1991.

MENON, T; BLOUNT, S. The messenger bias: A relational model of knowledge valuation. Research in Organizational Behavior, v.25, n., p.137-186, 2003.

MILLER, C. D; SALKIND, J. N. Qualitative data analysis software. In: MILLER, C. D; SALKIND, J. N. Handbook of research design \& social measurement. 6th ed., Thousand Oaks: Sage, 2002. p. 165-179.

NAG, R; CORLEY, K. G; GIOIA, D. A. The intersection of organizational identity, knowledge, and practice: attempting strategic change via knowledge grafting. Academy of Management Journal, v. 50, n. 4, p. 821-847, 2007.

NONAKA, I; TOYAMA, R; BYOSIÈRE, P. A theory of organizational knowledge creation: understanding the dynamic process of creating knowledge. In: KIERLES, M; NONAKA, I. Handbook of organizational learning \& knowledge. Oxford: Oxford University Press, 2001. p. 491-517.

OBORN, E; DAWSON, S. Learning across communities of practice: an examination of multidisciplinary work. British Journal of Management, v. 21, n. 4, p. 843858,2010

PEIRCE, C. S. The Essential Peirce, Volume 2: Selected Philosophical Writings, 1893-1913. Bloomington: Indiana University Press, 1998.

PENROSE, E. Teoria do crescimento da firma. São Paulo: Unicamp, 2006, original 1959.

PRAHALAD, C. K; HAMEL, G. The core competence of the corporation. Harvard Business Review, v. 68, n. 3, p. 79-91, 1990 
RAVISHANKAR, M. N; PAN, S. L. The influence of organizational identification on organizational knowledge management. Management Science, v. 36, n. 2, p. 221-234, 2008.

ROBERTSON, M; SCARBROUGH, H; SWAN, J. Knowledge creation in professional service firms: institutional effects. Organization Studies, v. 24, n. 6, p. 831-857, 2003.

SCHWAR, G. M. Z; WATSON, B. M. The influence of perceptions of social identity on information technology-enabled change. Group \& Organization Management, v. 30, n. 3, p. 289-318, 2005.

SPENDER, J. C; GRANT, R. M. Knowledge and the firm: overview. Strategic Management Journal, v. 17, p. 5-9, 1996.

STARBUCK, W. H; BARNETT, M. L; BAUMARD, P. Payoffs and pitfalls of strategic learning. Journal of Economic Behavior E Organization, v. 66, n. 1, p. 7-21, 2008.

STARBUCK, W. H; HEDBERG, B. How organizations learn from success and failure. In: DIERKES, M; NONAKA, I. Handbook of organizational learning \& knowledge. Oxford: Oxford University Press, 2001. p. 327-349.

TAJFEL, H. Differentiation between social groups: Studies in the social psychology of intergroup relations. Oxford: Academic Press. 1978. 474 p.

TAJFEL, H.; TURNER, J. C. An integrative theory of intergroup conflict. The social psychology of intergroup relations, v. 33, p. 47, 1979.

TURNER, J. C. Towards a cognitive redefinition of the social group. In H. Tajfel (Ed.), Social identity and intergroup relations. p. 15-40. Cambridge: Cambridge University Press, 1982.

TURNER, J. C. Social categorization and the self-concept: A social cognitive theory of group behavior. In LAWLER, E. J. (Ed.), Advances in group processes: Theory and research, vol. 2: 77-122. Greenwich: JAI Press, 1985.

WARING, J; CURRIE, G. Managing expert knowledge: organizational challenges and managerial futures for the UK medical profession. Organization Studies, v. 30, n 7, p. 755-778, 2009.

WEICK, K. Sensenmaking in organizations. Thousand Oaks: Sage, 1995.
WENGER, E. Communities of practice and social learning systems. Organizations, v. 7, n. 2, p. 225-246, 2000.

WENGER, E. Communities of practice: learning, meaning and identity. 18th ed. Cambridge: Cambridge University, 2008, original 1998.

WERNERFELT, B. A resource based view of the firm. Strategic Management Journal, v. 5, n. 3, p. 171-180, 1984.

WHETTEN, D. A; MACKEY, A. A social actor conception of organizational identity and its implications for the study of organizational reputation. Business \& Society, v. 41, n. 1, p. 393-414, 2002. 